Cite this: Mol. BioSyst., 2014, 10, 412

Received 20th September 2013 Accepted 6th December 2013

DOI: 10.1039/c3mb70420c

www.rsc.org/molecularbiosystems

\section{Insights into the role of the beta-2 microglobulin $D$-strand in amyloid propensity revealed by mass spectrometry $\dagger$}

\author{
Aneika C. Leney, $\ddagger$ Clare L. Pashley, Charlotte A. Scarff, Sheena E. Radford* and \\ Alison E. Ashcroft*
}

\begin{abstract}
In vivo beta-2 microglobulin $\left(\beta_{2} \mathrm{~m}\right)$ forms amyloid fibrils that are associated with the disease dialysis-related amyloidosis. Here, electrospray ionisation-ion mobility spectrometry-mass spectrometry has been used to compare the oligomers formed from wild-type $\beta_{2} m$ with those formed from a variant of the protein containing a single point mutation in the D strand, $\mathrm{H} 51 \mathrm{~A}$, during in vitro fibril assembly. Using the amyloidbinding fluorescent dye, Thioflavin T, to monitor fibrillation kinetics, H51A was shown to exhibit a two-fold increase in the lag-time of fibril formation. Despite this, comparison of the oligomeric species observed during the lag-time of self-aggregation indicated that H51A had a higher population of oligomers, and formed oligomers of higher order, than wild-type $\beta_{2} \mathrm{~m}$. The cross-sectional areas of the oligomers arising from $\mathrm{H} 51 \mathrm{~A}$ and wild-type protein were indistinguishable, although the $\mathrm{H} 51 \mathrm{~A}$ oligomers were shown to have a significantly higher kinetic stability on account of their reluctance to undergo sub-unit exchange when mixed with $15 \mathrm{~N}$-labelled protein. Together the data reveal a significant effect of His51, and thus that of the $\mathrm{D}$-strand sequence, on amyloid formation. The results also highlight the power of mass spectrometry in probing complex biochemical mechanisms in real-time.
\end{abstract}

\section{Introduction}

The correct folding of proteins into their native, functional states is highly dependent on protein sequence, the environment, and the presence of additional factors including chaperones. ${ }^{1,2}$ If the balance of these conditions is altered, protein misfolding and/or aggregation can occur resulting in some cases in long, straight, unbranched polymeric structures with a characteristic cross- $\beta$ structure, termed amyloid. ${ }^{3,4}$ Here, we focus on the amyloid-forming protein beta-2 microglobulin $\left(\beta_{2} \mathrm{~m}\right)$ whose aggregation in humans is the primary causative agent of the disease dialysis-related amyloidosis. ${ }^{5,6} \beta_{2} \mathrm{~m}$ is the non-covalently bound light chain of the major histocompatibility complex class 1 (MHC 1) and in healthy subjects is excreted through the kidneys after dissociation from the MHC 1. In patients undergoing dialysis, this excretion pathway is unavailable and $\beta_{2} \mathrm{~m}$ protein levels in the body rise, resulting eventually in their self-aggregation into amyloid fibrils.

Astbury Centre for Structural Molecular Biology and School of Molecular and Cellular Biology, Faculty of Biological Sciences, University of Leeds, Leeds, LS2 9JT, UK. E-mail: s.e.radford@leeds.ac.uk, a.e.ashcroft@leeds.ac.uk;

Fax: +44 (o)113 343 7273; Tel: +44 (o)113 343 3170, +44 (o)113 3437273

$\dagger$ Electronic supplementary information (ESI) available. See DOI: 10.1039/ c3mb70420c

\$ Current address: Alberta Glycomics Centre and Department of Chemistry, University of Alberta, Edmonton, Alberta, T6G 2G2, Canada. $\beta_{2} \mathrm{~m}$ is a 99-residue, $\sim 12 \mathrm{kDa}$ protein. In its native state, $\beta_{2} \mathrm{~m}$ consists of seven $\beta$-strands (A-G) arranged as two $\beta$-sheets involving the $\beta$-strands ABED and CFG in a $\beta$-sandwich fold connected by a disulphide bond between residues Cys 25 and Cys80 (Fig. 1A). ${ }^{7}$ In vitro $\beta_{2} \mathrm{~m}$ remains soluble at $\mathrm{pH} 7.5$ with no evidence of amyloid formation even after 100 days of incubation at $37^{\circ} \mathrm{C} .{ }^{8-10}$ However, insoluble amyloid fibrils do form in hours to days in vitro, dependent on the precise solution conditions and agitation rate, in low ionic strength $(<100 \mathrm{mM})$ buffer at $\mathrm{pH}$ 2.5. ${ }^{11-13}$ In this environment, the highly dynamic acid-unfolded $\beta_{2} \mathrm{~m}$ protein self-aggregates into long, straight, unbranched, twisted fibrils displaying all the hallmarks of amyloid. ${ }^{13-18}$ Thus, the timescale of these experiments is ideally suited for model investigations into the self-aggregation process.

Electrospray ionisation-mass spectrometry and its combination with ion mobility spectrometry (ESI-IMS-MS) have led to significant advances in the understanding of the mechanism of amyloid fibril formation, in particular concerning the specific oligomeric intermediates formed during self-aggregation. ${ }^{19,20}$ The study of these transient oligomers is particularly important as their presence correlates well with amyloid disease progression ${ }^{21-23}$ and, furthermore, it has been suggested that these oligomers may well be the toxic species rather than the fibril end-products. ${ }^{24-26}$ Previous ESI-IMS-MS analyses have enabled the identification and separation of co-populated, non-covalently bound $\beta_{2} \mathrm{~m}$ 
A

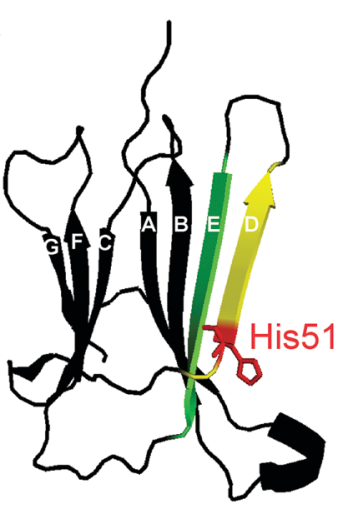

C

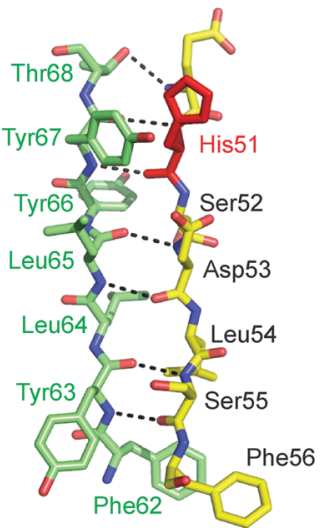

B

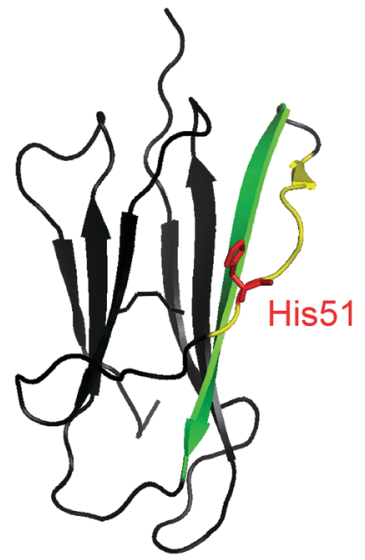

$\mathrm{D}$

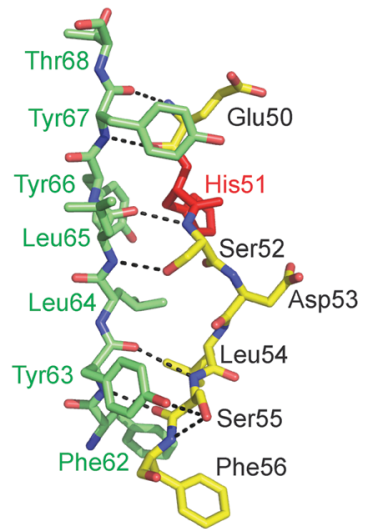

Fig. 1 Ribbon structures of wild-type human $\beta_{2} m$ highlighting the different conformations of the $\mathrm{D}$ strand (yellow) between (A) monomeric, apo$\beta_{2} \mathrm{~m}$ (PDB file: $\left.1 \mathrm{LDS}\right)^{7}$ and (B) the MHC 1-bound holo form (PDB file: $2 \times 70$ ). The hydrogen bond contacts (black dashed lines) between the D- (yellow) and $\mathrm{E}$ - (green) strands of $\beta_{2} \mathrm{~m}$ are shown in the case of both monomeric, apo- $\beta_{2} \mathrm{~m}(\mathrm{C})$ and the MHC 1-bound holo form (D). The location of His51 (red) is highlighted on each structure.

oligomers based on their charge, shape and mass from within the highly heterogeneous mixtures present during amyloid formation. $^{27,28}$ ESI-IMS-MS rotationally averaged collision cross-sectional area (CCS) estimations of the $\beta_{2} \mathrm{~m}$ oligomers formed at $\mathrm{pH} 2.5$ have suggested that these species adopt a stacked conformation of end-to-end $\beta_{2} \mathrm{~m}$ monomers rather than an alternative, more compact, globular arrangement. ${ }^{27}$

The current study utilises ESI-IMS-MS, in parallel with mutagenesis and biochemical techniques, to focus on understanding the effect of the amino acid sequence comprising the native $\mathrm{D}$ $\beta$-strand of $\beta_{2} \mathrm{~m}$ on fibrillogenesis, a region which is known to form important structural contacts with the $\alpha$-chain of the MHC $1 .^{29}$ Interestingly, on release from the MHC 1 , this $\beta$-strand becomes highly dynamic ${ }^{30}$ and is known to be aggregation prone, ${ }^{31}$ suggesting a key role for the D-strand sequence in the self-aggregation of the protein monomer. ${ }^{9,29,32}$ The D-strand of $\beta_{2} \mathrm{~m}$ is involved in the noncovalent binding of $\beta_{2} \mathrm{~m}$ to the heavy chain of the MHC 1 (Fig. 1). Available crystal structures show a bulged D-strand in complex with the heavy chain of the MHC 1 (Fig. 1B and D) with residue Asp53 (the $\beta$-bulge residue at the centre of the $\mathrm{D}$-strand sequence) hydrogen-bonded to Arg35 on the heavy chain of the MHC $1 .^{35}$ On dissociation from the MHC 1 complex, the D-strand becomes solvent exposed and thus may be involved in initiating $\beta_{2} \mathrm{~m}$ aggregation. Indeed, X-ray crystallography and NMR studies have indicated that the D-strand is highly dynamic, adopting multiple conformations in solution ${ }^{7,29,36-38}$ with molecular dynamic simulations showing a straight D-strand to be populated on decreasing $\mathrm{pH}^{39}$ Although the exact $\beta_{2} \mathrm{~m}$ oligomeric structure at low $\mathrm{pH}$ still remains to be elucidated, experiments involving covalent labelling combined with mass spectrometry have suggested a role of the D-strand sequence in the oligomeric interface of the $\beta_{2} \mathrm{~m}$ dimer and tetramer at neutral $\mathrm{pH}$ in the presence of $\mathrm{Cu}^{2+} \cdot{ }^{40,41}$ Mutations in the D-strand of $\beta_{2} \mathrm{~m}$ have been shown previously to alter the lag-time of fibril formation at $\mathrm{pH} 2.5$ suggesting that the $\mathrm{D}$-strand sequence may play a role in fibrillogenesis. ${ }^{33,42}$ A single point mutation, H51A, in particular, has been shown to increase the lag-time of fibrillogenesis in vitro by up to two-fold, even though the eventual fibril morphology, as judged by negative stain electron microscopy (EM), remained comparable with that of the WT $\beta_{2} \mathrm{~m}$ protein. ${ }^{33}$ Interestingly, on transition of the D-strand from the bent to the straight conformation (Fig. 1), His51 rotates through $180^{\circ}$ and is no longer involved in H-bonding to Tyr66 (Fig. 1C and D). Thus, substitution of residue 51 to alanine is thought to cause slight structural perturbations in the D-strand conformation which result in the increased lag-time of amyloid formation observed.

Here, oligomers originating from wild-type (WT) $\beta_{2}$ m under in vitro fibril-forming conditions have been compared with oligomers formed from H51A, the construct resulting from a single point mutation within the D-strand of the WT sequence. Despite both proteins self-aggregating into fibrils of very similar morphology, the lag-times of assembly are different. Furthermore, the shape (in terms of CCS), population and dynamics of the oligomers observed during fibril formation have been investigated to provide insights into the role of the sequence that comprises the D-strand of $\beta_{2} \mathrm{~m}$ in the amyloid assembly process.

\section{Materials and methods}

\section{Reagents}

Ammonium formate and thioflavin $\mathrm{T}$ (ThT) were purchased from Sigma-Aldrich (Gillingham, Dorset, UK). ${ }^{14} \mathrm{~N}$ WT $\beta_{2} \mathrm{~m},{ }^{14} \mathrm{~N}$ H51A and ${ }^{15} \mathrm{~N}$ wild-type (WT) $\beta_{2}$ m were prepared as described previously. ${ }^{33}{ }^{15} \mathrm{~N}$ H51A was expressed in ${ }^{15} \mathrm{~N}$-enriched minimal media and purified as described. ${ }^{33}$ All proteins were determined to be monomeric by gel filtration, shown to be pure by SDS-PAGE analysis, and their molecular mass determined using ESI-MS. The molecular masses for WT and H51A were accurate to within $0.01 \%$ of those predicted based on amino acid composition (11860.3 Da and 11794.3 Da, respectively). Protein concentrations were calculated from the $\mathrm{A}_{280}$ using the extinction coefficient $20065 \mathrm{M}^{-1} \mathrm{~cm}^{-1}$.

\section{Formation of amyloid fibrils from $\beta_{2} \mathrm{~m}$ WT and H51A}

$\beta_{2} \mathrm{~m}$ and H51A (0.4 $\left.\mathrm{mg} \mathrm{mL}^{-1}\right)$ were incubated separately in $100 \mathrm{mM}$ ammonium formate $\left(\mathrm{pH} 2.5 ; 37^{\circ} \mathrm{C}\right)$ shaking at $600 \mathrm{rpm}$ 
using a Thriller Thermoshaker Incubator (PEQLAB Ltd, Southampton, UK). Fibril growth kinetics were monitored using ThT fluorescence. $50 \mu \mathrm{L}$ aliquots were removed at regular intervals and diluted with $950 \mu \mathrm{L}$ ThT $(20 \mu \mathrm{M})$ in $100 \mathrm{mM}$ ammonium formate $\mathrm{pH} 2.5$. ThT fluorescence was measured in a PTI Quantamaster C-61 spectrofluorimeter using an excitation wavelength of $444 \mathrm{~nm}$ and emission at $480 \mathrm{~nm}$ with slit-widths of $4.5 \mathrm{~nm}$. At the end-point of the reaction, samples were taken for negative stain transmission electron microscopy (EM). Simultaneous to the ThT reading, a $10 \mu \mathrm{L}$ sample of the $\beta_{2} \mathrm{~m}$ variant in $100 \mathrm{mM}$ ammonium formate $\mathrm{pH} 2.5$ was removed separately for mass spectrometric analysis. To ensure accuracy in lag-time estimations of fibril formation between experiments, WT $\beta_{2} \mathrm{~m}$ was analysed alongside the $\beta_{2} \mathrm{~m}$ variant $\mathrm{H} 51 \mathrm{~A}$ on each day of analysis. The lag-time was obtained by fitting a tangent to the steepest part of the normalised ThT growth phase and the time at which the line intersected the baseline was taken as the lag-time. ${ }^{33,34}$ The average fold change in lag-time compared with WT $\beta_{2} \mathrm{~m}$ is reported along with the standard deviation between five replicates.

\section{Fibril yield}

$\beta_{2} \mathrm{~m}$ and H51A (0.4 $\left.\mathrm{mg} \mathrm{mL} \mathrm{mL}^{-1}\right)$ were incubated under the fibril forming conditions described above. After $46 \mathrm{~h}$, samples were taken and the fibrils pelleted by centrifugation $(13000 \mathrm{~g}, 30 \mathrm{~min})$. The supernatant in each case was analysed by SDS-PAGE along with an identical sample taken prior to fibril formation.

\section{Electron microscopy}

$10 \mu \mathrm{l}$ of fibrils in $100 \mathrm{mM}$ ammonium formate $\mathrm{pH} 2.5$ (i.e., reaction end products) were placed on freshly ionised formvar- and carboncoated EM grids for $30 \mathrm{~s}$. The grids were then blotted with filter paper to remove excess solvent and the samples stained with $2 \%(\mathrm{w} / \mathrm{v})$ uranyl acetate for $30 \mathrm{~s}$. The grids were blotted again and air-dried before analysis. All images were taken using a CM10 electron microscope (Phillips Research, Eindoven, Netherlands) operating at $80 \mathrm{keV}$.

\section{ESI-IMS-MS}

ESI-IMS-MS experiments were performed on a Synapt HDMS hybrid quadrupole-IMS-oaTOF (Waters Ltd, Manchester, UK) mass spectrometer interfaced with a NanoMate Triversa nanoESI sample inlet and source (Advion Biosystems Inc. Ithaca, NY, USA). Positive nanoESI was performed using a capillary voltage of $1.75 \mathrm{kV}$ and a nitrogen nebulising gas pressure of 0.7 p.s.i. A cone voltage of $170 \mathrm{~V}$ and a backing pressure of 3.6 mbar were used to observe the $\beta_{2} \mathrm{~m}$ oligomers. The ion accelerating voltages into the trap and transfer $T$-wave were set at $6 \mathrm{~V}$ and $20 \mathrm{~V}$, respectively. The wave height was ramped from 4-12.5 $\mathrm{V}$ with a speed of $300 \mathrm{~m} \mathrm{~s}^{-1}$. For all mass spectrometry experiments, CsI clusters were used to calibrate the mass spectrometer and the raw data processed using MassLynx v.4.1 software (Waters Ltd, Manchester, UK) in combination with Driftscope v.3.0.

\section{${ }^{14} \mathrm{~N} /{ }^{15} \mathrm{~N}-\beta_{2}$ m oligomer exchange}

For subunit exchange measurements carried out at $50 \%$ of the lag-time of fibril growth, the lag-time was estimated (using previously acquired data) and at the correct time-point during fibril growth, $100 \mu \mathrm{L}$ of the ${ }^{14} \mathrm{~N} \beta_{2}$ m WT or ${ }^{14} \mathrm{~N} \mathrm{H} 51 \mathrm{~A}$ was mixed in a $1: 1 \mathrm{v} / \mathrm{v}$ ratio with $100 \mu \mathrm{L}$ of predominantly monomeric ${ }^{15} \mathrm{~N}$ WT $\beta_{2} \mathrm{~m}$ or ${ }^{15} \mathrm{~N}$ H51A (incubated on ice throughout the time course), respectively. Mass spectra were acquired after $1 \mathrm{~min}$ and 50 min of mixing. All samples were incubated in the 96-well plate within the NanoMate Triversa device at $20{ }^{\circ} \mathrm{C}$ throughout the subunit exchange experiments. The extent of subunit exchange was determined by comparing the area under the peaks corresponding to the ${ }^{14} \mathrm{~N}$ WT $\beta_{2} \mathrm{~m} /{ }^{14} \mathrm{~N}$ H51A and the ${ }^{15} \mathrm{~N}$ WT $\beta_{2} \mathrm{~m} /{ }^{15} \mathrm{~N}$ H51A oligomers analysed at $t=1 \mathrm{~min}$ with the mixed ${ }^{14} \mathrm{~N}$ WT $\beta_{2} \mathrm{~m}:{ }^{15} \mathrm{~N}$ WT $\beta_{2} \mathrm{~m}$ and ${ }^{14} \mathrm{~N}$ H51A: ${ }^{15} \mathrm{~N}$ H51A subunit exchanged oligomers, respectively.

\section{Sedimentation velocity analytical ultracentrifugation}

Sedimentation velocity experiments were carried out at $25{ }^{\circ} \mathrm{C}$ using a Beckman Optima XL-I analytical ultracentrifuge (Beckman, Palo Alto, CA) using an An-60 Ti rotor with conventional aluminium double-sector centrepieces with a rotor speed of $40000 \mathrm{rpm}$. Samples $\left(0.4 \mathrm{mg} \mathrm{mL}^{-1}\right)$ were prepared in the buffer used for MS analyses by overnight dialysis $4{ }^{\circ} \mathrm{C}$. Radial absorbance scans at $280 \mathrm{~nm}$ were collected at $300 \mathrm{~s}$ intervals and the data were analysed using SEDFIT. ${ }^{43}$

\section{Results and discussion}

\section{H51A increases the lag-time of in vitro fibril formation compared with wild-type $\beta_{2}$ m}

Here, ESI-MS was used to investigate the nature of the oligomers formed during H51A fibril formation in order to probe how this single point mutation retards the rate of amyloid formation at low $\mathrm{pH}$ in vitro. To achieve this, fibril formation was performed independently for both wild-type (WT) $\beta_{2}$ m and H51A by incubating each protein at $37{ }^{\circ} \mathrm{C}$ with agitation $(600 \mathrm{rpm})$ in $100 \mathrm{mM}$ ammonium formate at $\mathrm{pH} 2.5 .^{27,33}$ Under these conditions, WT $\beta_{2} \mathrm{~m}$ and $\mathrm{H} 51 \mathrm{~A}$ both form amyloid-like fibrils with lag-dependent kinetics, as shown by ThT fluorescence (Fig. 2A). In each case, negative stain EM analysis indicated that the fibrils produced exhibit long, straight morphologies (Fig. 2B), similar to the architecture of ex vivo fibrils. Consistent with previous results carried out using non-volatile (i.e., MS-incompatible) buffers, ${ }^{33}$ the lag-time of fibril formation is increased $\sim$ two-fold for H51A compared with WT $\beta_{2}$ m (Fig. 2A and C), thus supporting a potential role of His51 in $\beta_{2} \mathrm{~m}$ amyloid fibril formation.

H51A populates higher order oligomers during the lag-time of in vitro fibril assembly compared with wild-type $\beta_{2} \mathbf{m}$

ESI-MS and ESI-IMS-MS were used to investigate the populations of, and any structural differences between, the oligomeric intermediates formed by $\mathrm{H} 51 \mathrm{~A}$ and $\mathrm{WT} \beta_{2} \mathrm{~m}$ during fibril assembly, which may explain the difference in the kinetics observed and reveal insights into the amyloid formation mechanism. On initial 

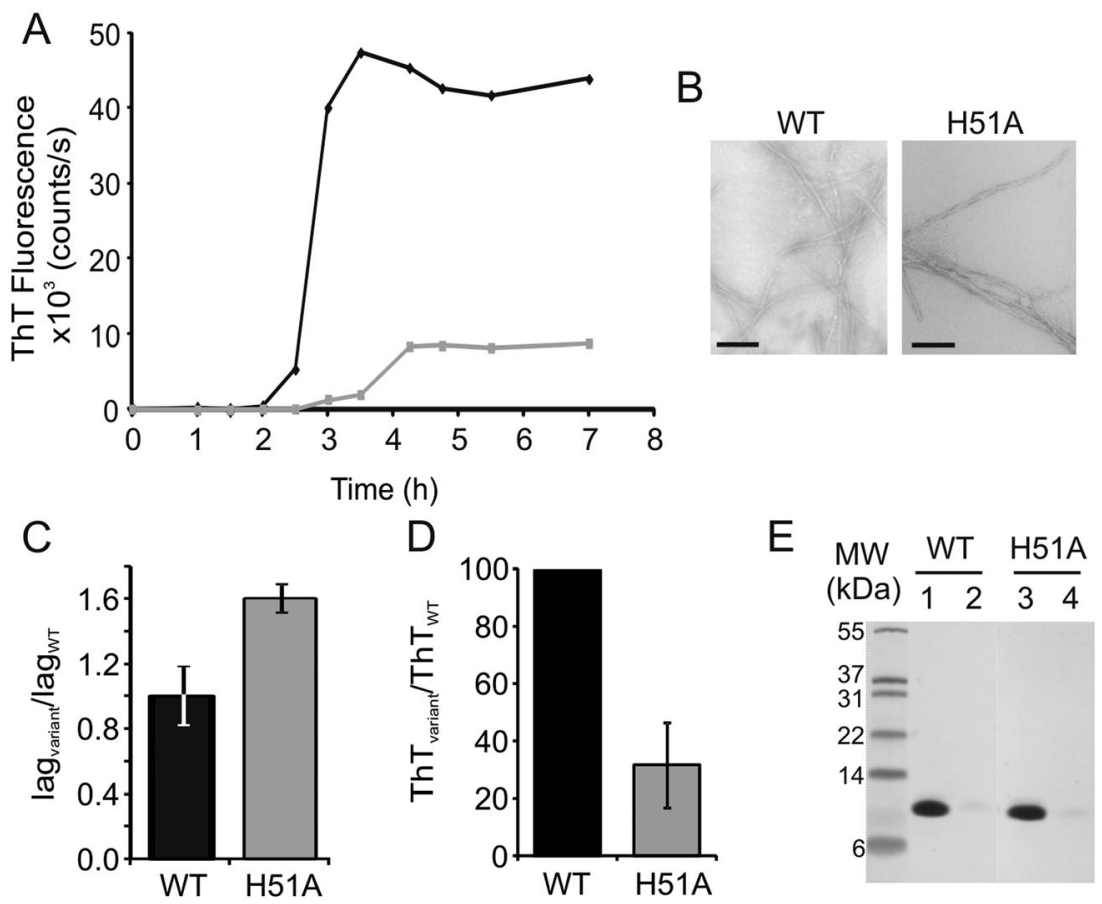

Fig. 2 (A) Graph showing ThT kinetics of fibril formation for WT $\beta_{2} m$ (black) and H51A (grey); one trace from five replicates is shown for each for simplicity. (B) Electron microscopy images of fibrils formed in $100 \mathrm{mM}$ ammonium formate $\mathrm{pH} 2.5,37^{\circ} \mathrm{C}, 600 \mathrm{rpm}$, from WT $\beta_{2} \mathrm{~m}$ and the $\beta_{2} \mathrm{~m}$ variant $\mathrm{H} 51 \mathrm{~A}$; the scale bar in each case represents $200 \mathrm{~nm}$. (C) Fold change in lag-time of H51A compared with WT $\beta_{2} \mathrm{~m}$; the average of five replicates is shown together with the standard deviation between replicates. (D) Final H51A ThT fluorescence signal expressed as a percentage of the WT $\beta_{2} \mathrm{~m}$ final ThT fluorescence signal; the average and standard deviation between five replicates is shown. (E) SDS-PAGE analysis of WT $\beta_{2} \mathrm{~m}$ (lane 1) and H51A (lane 3) prior to fibril formation compared with the remaining soluble fractions post-fibril formation (lanes 2 and 4 for WT $\beta_{2} m$ and H51A, respectively).

dilution of WT $\beta_{2} \mathrm{~m}$ into the fibril-forming buffer $(100 \mathrm{mM}$ ammonium formate, $\mathrm{pH} 2.5$ to give a final protein concentration of $0.4 \mathrm{mg} \mathrm{mL}^{-1}$ ), an aliquot was removed and analysed. At the earliest time-point measurable $(1 \mathrm{~min})$ the ESI mass spectrum was dominated by monomer ions (Fig. S1, ESI $\dagger$ ) together with low intensity dimer, trimer and tetramer ions (the latter highlighted in Fig. 3A). In contrast, in addition to monomer, higher order oligomers from dimer to pentamer, inclusively, were observed at higher relative intensities in the ESI mass spectrum upon dilution of H51A into the fibril-forming buffer (Fig. 3B, Fig. S1, ESI $\dagger$ ) suggesting that the $\mathrm{H} 51 \mathrm{~A}$ variant is significantly more prone to form oligomers compared with $\mathrm{WT} \beta_{2} \mathrm{~m}$ at low $\mathrm{pH}$, despite having a longer lag-time of fibril assembly.

The ESI-IMS-MS driftscope plots of WT $\beta_{2} \mathrm{~m}$ and the variant H51A acquired on initial dilution into fibril-forming buffer illustrate the added dimension of IMS in its ability to separate oligomers of different sizes including those ions of the same $\mathrm{m} / \mathrm{z}$ but of both different mass and different charge (Fig. 3C and D, respectively). For both proteins, oligomers were separated within these highly heterogeneous populations, allowing each species to be assigned uniquely based on its $\mathrm{m} / \mathrm{z}$ values and charge states. With the extra separation dimension, at the initial time-point at the start of the lag-phase oligomers up to and including the pentamer could be detected for WT $\beta_{2} \mathrm{~m}$ (as described previously ${ }^{27}$ ), and oligomers up to and including the hexamer were observed for H51A (Fig. 3C and D, respectively). Furthermore, the ESI-IMS-MS data show clearly that the higher order oligomers are significantly more populated in the case of H51A compared with WT $\beta_{2} \mathrm{~m}$.

A control experiment was performed to compare the extent of oligomerisation of WT $\beta_{2} \mathrm{~m}$ and H51A in solution and thus to verify the legitimate presence of the oligomers observed by use of gas-phase mass spectrometry analyses. Thus, solutions of both proteins in the buffers used for the mass spectrometry studies were subjected independently to sedimentation velocity analysis (Fig. S2, ESI $\dagger$ ). In both cases, protein monomer together with a distribution of oligomers were observed. In agreement with the mass spectrometry data, oligomers were found in solution for both WT $\beta_{2} \mathrm{~m}$ and H51A, with the difference in peak widths of the distribution of species found suggestive of different rates of interconversion between different oligomeric forms for $\mathrm{H} 51 \mathrm{~A}$ compared with WT $\beta_{2} \mathrm{~m}$. These results are consistent with our previous WT $\beta_{2} \mathrm{~m}$ studies in which protein aggregates observed in the gas-phase were shown to reflect the oligomers detected in solution using a similar analysis. ${ }^{44}$

To monitor the progression of self-assembly and fibril formation, WT $\beta_{2} \mathrm{~m}$ and $\mathrm{H} 51 \mathrm{~A}$ were incubated separately at $37^{\circ} \mathrm{C}$ in $100 \mathrm{mM}$ ammonium formate, $\mathrm{pH} 2.5$, with agitation at $600 \mathrm{rpm}$. At various time-points, aliquots were removed for ESI-IMS-MS analysis, with simultaneous ThT fluorescence analysis to confirm the duration of the lag-phase of fibril formation. The ESI-IMS-MS data for WT $\beta_{2} \mathrm{~m}$ and $\mathrm{H} 51 \mathrm{~A}$ at $50 \%$ of their individual lag-phases of fibril formation are shown in Fig. $3 \mathrm{E}$ and F, respectively. These data indicate that the population of oligomeric species 

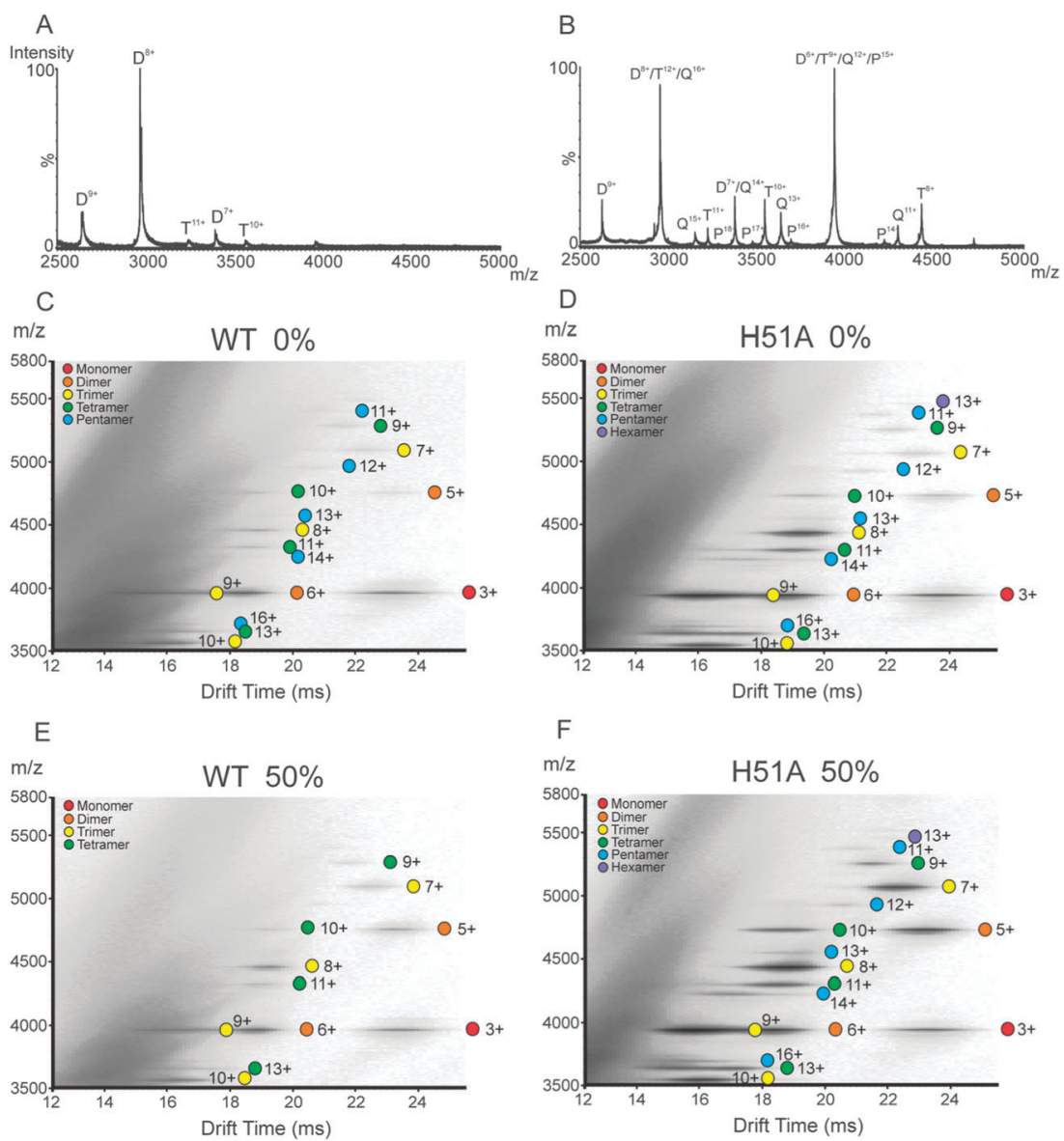

Fig. 3 ESI-MS mass spectra highlighting the oligomers present ( $m / z$ 2500-5000) for (A) WT $\beta_{2} m$ and (B) H51A, immediately after dilution into 100 mM ammonium formate, $\mathrm{pH}$ 2.5. The charge states corresponding to the oligomers are highlighted: dimer (D), trimer (T), tetramer (Q) and pentamer (P). The majority of the ions originating from the WT $\beta_{2} m$ and H51A monomers appear $\leq m / z 2500$ (Fig. S1, ESI $\dagger$ ). No noticeable differences in the charge state distributions for H51A and WT $\beta_{2}$ m monomers were observed. ESI-IMS-MS driftscope plots of (C) WT $\beta_{2} m$ and (D) H51A immediately after dilution of the proteins into the fibril-forming buffer ( $100 \mathrm{mM}$ ammonium formate, $\mathrm{pH}$ 2.5) i.e., at $0 \%$ through their lag-phases of amyloid fibril formation; and (E) WT $\beta_{2} \mathrm{~m}$ and (F) H51A at 50\% through their respective lag-phases of amyloid fibril formation (monomer $=$ red, dimer $=$ orange, trimer $=$ yellow, tetramer $=$ green, pentamer $=$ blue, hexamer $=$ purple).

for the WT protein decreases during the lag-phase, with ions corresponding to the $12+$ to $16+$ charge states of the pentamer no longer being observed. This suggests that the higher order oligomers observed at the start of fibril formation have extended rapidly into pre-fibrillar species and/or into amyloid fibrils that are undetectable using ESI-IMS-MS analysis alone. By the end of the lag-phase, all of the oligomer peaks have disappeared and the sample becomes very challenging to electrospray into the gas-phase due to the high population of insoluble amyloid fibrils present (data not shown). The short lifetime of the oligomers observed suggest that they are either on-pathway species, or that they are transient off-pathway intermediates of fibrillation.

By contrast with the population of WT $\beta_{2} \mathrm{~m}$ oligomers, the H51A higher order oligomers are still highly populated at $50 \%$ of the lag-phase (Fig. 3F). On extraction of the lowest charge state ions corresponding to the WT $\beta_{2} \mathrm{~m}$ and $\mathrm{H} 51 \mathrm{~A}$ monomer (i.e., $3+$ ions) and oligomers (i.e., dimer $5+$, trimer $7+$, tetramer 9+, pentamer 11+) from the IMS driftscope plots, the reproduced ESI mass spectra show clearly that a significantly lower abundance of oligomers are present for WT $\beta_{2} \mathrm{~m}$ (Fig. 4A) compared with the abundance of oligomers observed for the H51A variant (Fig. 4B) at this time. In addition, a comparison of the separated isobaric monomer $3+$, dimer $6+$ and trimer $9+$ ions originating from H51A at $\mathrm{m} / \mathrm{z} \sim 4000$ indicate that the dimer and trimer are more abundant than the monomer in contrast to the respective abundances of these three species in the case of WT $\beta_{2} \mathrm{~m}$ at $50 \%$ lag-phase (Fig. S3, ESI $\dagger$ ). One possible explanation for this observation is that $\mathrm{H} 51 \mathrm{~A}$ oligomers are less efficient at converting into amyloid fibrils compared with the WT $\beta_{2} \mathrm{~m}$ oligomers, and hence the H51A oligomers accumulate during the lag-phase. Interestingly, the IMS arrival time distributions of the H51A monomer $3+$, dimer $5+$, trimer $7+$, tetramer $9+$ and pentamer $11+$ ions (i.e., the lowest charge state ions in each case) are indistinguishable ( $<2 \%$ different) from those observed for the WT $\beta_{2}$ m monomer and oligomers indicating very similar CCSs (Fig. 4C and D). Overall, the extended lag-time of H51A fibril formation is accompanied by a higher population of oligomeric species that persist for longer periods than their WT $\beta_{2}$ m counterparts, but 

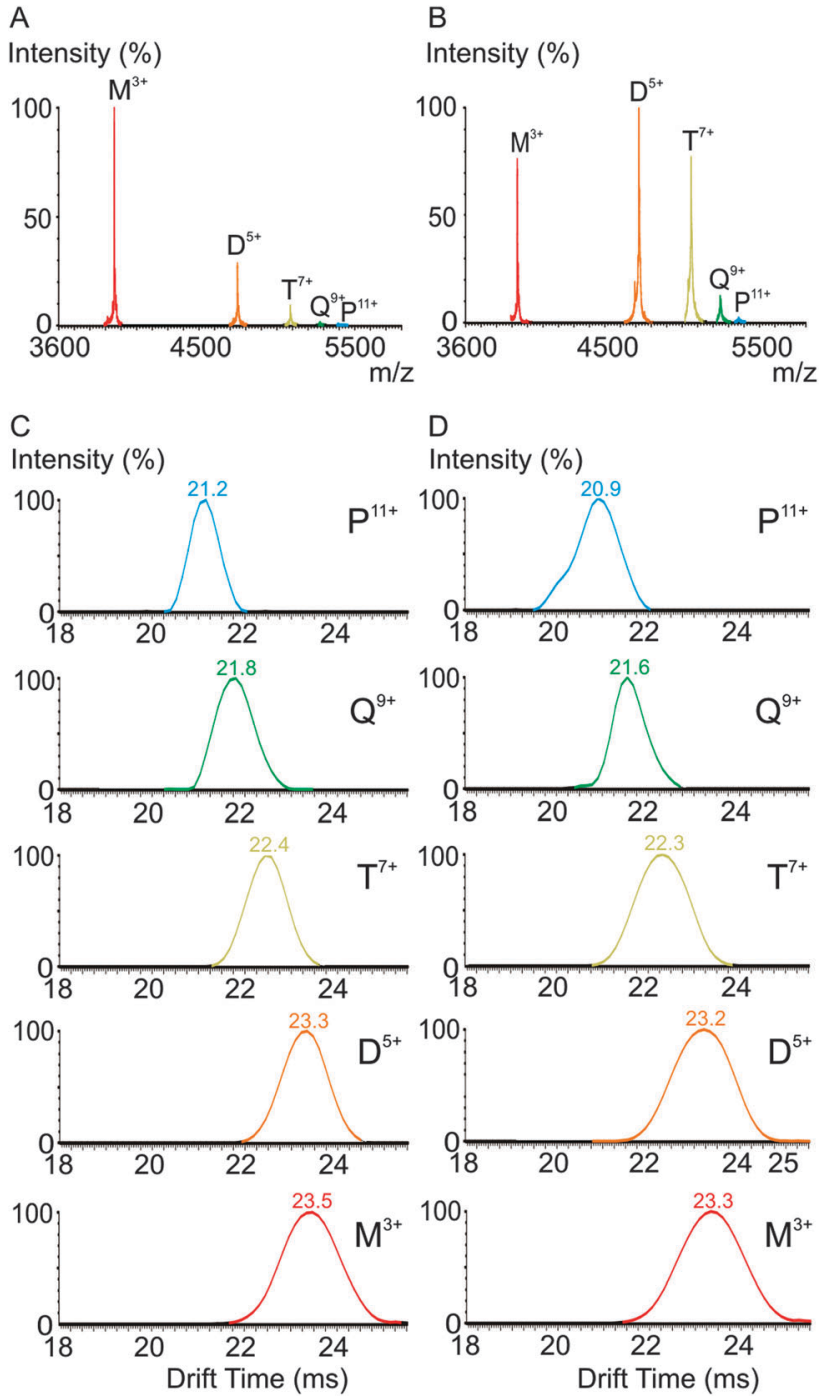

Fig. 4 ESI-IMS-MS mass spectra of the monomer (M) 3+ (red), dimer (D) $5+$ (orange), trimer (T) 7+ (yellow), tetramer (Q) 9+ (green) and pentamer (P) 11+ (blue) ions extracted from the IMS driftscope plot are shown for (A) WT $\beta_{2} m$ and (B) H51A at $50 \%$ of their respective lag-phases together with their individual ESI-IMS-MS arrival time distributions for (C) WT $\beta_{2} m$ oligomers and (D) H51A oligomers.

are indistinguishable based on their CCS values. This behaviour is consistent with the presence of on-pathway, or transient off-pathway, species that undergo relatively slow conversion to amyloid fibrils.

\section{H51A forms more stable, less dynamic oligomers compared with WT $\beta_{2} \mathrm{~m}$}

As the WT $\beta_{2} \mathrm{~m}$ and H51A oligomers showed no significant differences in their ESI-IMS-MS CCS values indicating that they cannot be distinguished in terms of their rotationally averaged shapes, the stabilities and dynamics of these oligomers were investigated further to determine whether other features could explain the differences in fibril formation kinetics of the two closely-related proteins. The dynamics of $\beta_{2} \mathrm{~m}$ oligomers formed during fibrillogenesis in vitro can be determined using subunit exchange experiments whereby ${ }^{14} \mathrm{~N}$ - and ${ }^{15} \mathrm{~N}-\beta_{2}$ m oligomers are mixed together and the rate of subunit exchange between the two species is monitored using ESI-IMS-MS. ${ }^{27,28}$ If the oligomers are highly dynamic entities and undergo rapid exchange with each other, then mixed oligomers containing both ${ }^{14} \mathrm{~N}$ - and ${ }^{15} \mathrm{~N}$-protein will be observed using mass spectrometry. For example, three peaks in a $1: 2: 1$ intensity ratio would be observed for a rapidly exchanging protein dimer corresponding to ${ }^{14} \mathrm{~N}:{ }^{14} \mathrm{~N},{ }^{14} \mathrm{~N}:{ }^{15} \mathrm{~N}$ and ${ }^{15} \mathrm{~N}:{ }^{15} \mathrm{~N}$ dimers. Similarly, four peaks in a $1: 3: 3: 1$ ratio would be observed for a rapidly exchanging trimer, and five peaks in a $1: 4: 6: 4: 1$ ratio for a rapidly exchanging tetramer (Fig. S4, ESI $\dagger$ ). Alternatively, if the oligomers are static entities, no exchange will occur and ions corresponding to all ${ }^{14} \mathrm{~N}$ - and all ${ }^{15} \mathrm{~N}$-proteins will be observed at a $1: 1$ intensity ratio (Fig. $\mathrm{S} 4$, ESI $\dagger$ ).

To determine whether the H51A oligomers are more kinetically stable (less dynamic) than their WT $\beta_{2} \mathrm{~m}$ counterparts, ${ }^{14} \mathrm{~N} /{ }^{15} \mathrm{~N}$ subunit exchange experiments were investigated for both WT $\beta_{2} \mathrm{~m}$ and $\mathrm{H} 51 \mathrm{~A}$ at $50 \%$ of their respective lag-phases. Hence, ${ }^{14} \mathrm{~N}-\mathrm{WT} \beta_{2} \mathrm{~m}$ and ${ }^{14} \mathrm{~N}-\mathrm{H} 51 \mathrm{~A}$ were incubated separately in $100 \mathrm{mM}$ ammonium formate, $\mathrm{pH} 2.5$ with agitation at $37^{\circ} \mathrm{C}$. At times corresponding to $50 \%$ of their lag-phases, ${ }^{15} \mathrm{~N}-\mathrm{WT} \beta_{2} \mathrm{~m}$ or ${ }^{15} \mathrm{~N}-\mathrm{H} 51 \mathrm{~A}$, respectively (held on ice throughout and therefore not aggregating), were added to their ${ }^{14} \mathrm{~N}$-labelled counterpart and any subunit exchange taking place was monitored using ESI-MS over a 50 minute time-course at room temperature. In all cases, the lag-phase was monitored in parallel using ThT fluorescence, and the presence of fibrils at the end of the lag-phase was confirmed by use of negative stain EM.

The extent of subunit exchange for ${ }^{14} \mathrm{~N}-\mathrm{WT} \quad \beta_{2} \mathrm{~m}$ and ${ }^{14} \mathrm{~N}-\mathrm{H} 51 \mathrm{~A}$ after 1 and 50 min of mixing with ${ }^{15} \mathrm{~N}-\mathrm{WT} \beta_{2} \mathrm{~m}$ or ${ }^{15} \mathrm{~N}-\mathrm{H} 51 \mathrm{~A}$ at $50 \%$ lag-phase, respectively, is shown in Fig. 5 .
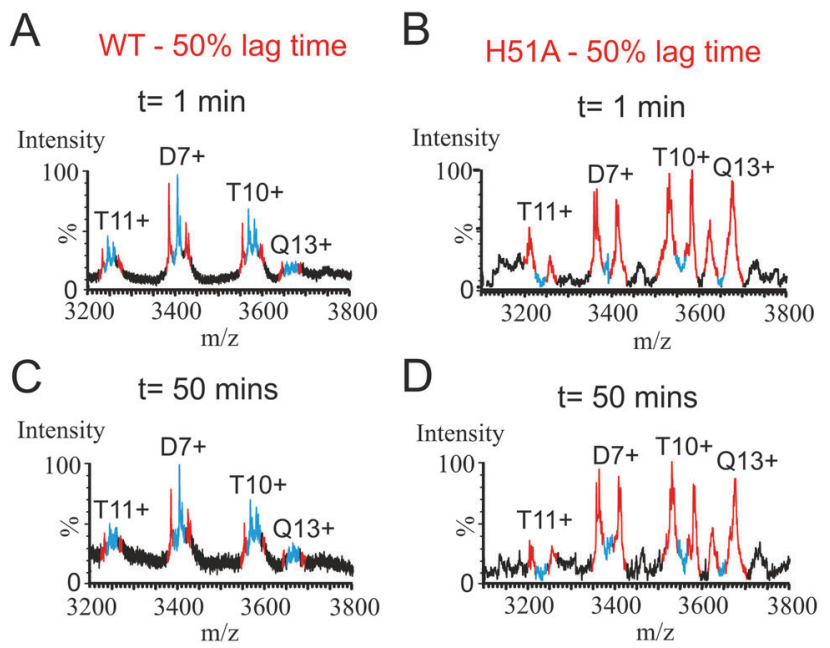

Fig. $5{ }^{14} \mathrm{~N}$ - and ${ }^{15} \mathrm{~N}$-labelled oligomeric $\beta_{2} \mathrm{~m}$ subunit exchange experiments illustrating the dimer (D) 7+, trimer (T) $10+$ and $11+$, and tetramer (Q) $13+$ ions. Samples of ${ }^{14} \mathrm{~N}-\mathrm{WT} \beta_{2} \mathrm{~m}(\mathrm{~A}, \mathrm{C})$ or ${ }^{14} \mathrm{~N}-\mathrm{H} 51 \mathrm{~A}(\mathrm{~B}, \mathrm{D})$ were mixed with ${ }^{15} \mathrm{~N}-\mathrm{WT} \beta_{2} \mathrm{~m}$ or ${ }^{15} \mathrm{~N}-\mathrm{H} 51 \mathrm{~A}$ monomer samples, respectively in a $1: 1(\mathrm{v} / \mathrm{v})$ ratio for $1 \mathrm{~min}(\mathrm{~A}, \mathrm{~B})$ or $50 \mathrm{~min}(\mathrm{C}, \mathrm{D})$ at $50 \%$ of the individual lag-phases for the two proteins. Peaks corresponding to all ${ }^{14} \mathrm{~N}$ - and all ${ }^{15} \mathrm{~N}$-oligomers are shown in red, and peaks corresponding to mixed ${ }^{14} \mathrm{~N} /{ }^{15} \mathrm{~N}$ oligomers are shown in blue. 
For WT $\beta_{2} \mathrm{~m}$, the extent of ${ }^{14} \mathrm{~N} /{ }^{15} \mathrm{~N}$-subunit exchange was complete as soon as the ${ }^{14} \mathrm{~N}$ - and ${ }^{15} \mathrm{~N}$-WT proteins were mixed together, suggesting that all of the WT $\beta_{2} \mathrm{~m}$ oligomers are dynamic in nature, in rapid equilibrium with exchanging monomeric subunits (Fig. 5A and C). Interestingly, for the H51A oligomers formed during the lag-phase, very little subunit exchange occurred on initial mixing of the ${ }^{14} \mathrm{~N}$ - and ${ }^{15} \mathrm{~N}-\mathrm{H} 51 \mathrm{~A}$ proteins (Fig. 5B), suggesting that these oligomers are more stable than the WT $\beta_{2}$ m oligomers, consistent with the results obtained using analytical ultracentrifugation. Indeed, no noticeable exchange was detected even after 50 minutes of incubation with ${ }^{15} \mathrm{~N}-\mathrm{H} 51 \mathrm{~A}$ (Fig. 5D). Importantly, the lack of significant subunit exchange for the H51A oligomers supports our conclusion that the H51A oligomers observed in the gas-phase are reflective of oligomers present in solution and do not occur during the ESI process. Indeed, if oligomer formation in H51A were to arise from nonspecific interactions occurring during the ESI process then complete subunit exchange would be expected to occur instantaneously upon mixing differently labelled protein subunits. The striking difference in subunit exchange kinetics for H51A oligomers compared with WT $\beta_{2} \mathrm{~m}$ is consistent with the increase observed in the lag-time of fibril formation (Fig. 2). Although the dynamics of the WT $\beta_{2} \mathrm{~m}$ and $\mathrm{H} 51 \mathrm{~A}$ oligomers differ considerably, their ESI-IMS-MS CCS values are very similar, suggesting that any structural differences in their ternary or quaternary structures that may affect their kinetic stability do not change the shape of the oligomers significantly.

The amino acid sequence corresponding to the D-strand of native $\beta_{2} \mathrm{~m}$ has been implicated in fibril formation based on structural, ${ }^{7,36,45}$ kinetic ${ }^{33}$ and peptide studies. ${ }^{31}$ Here we have shown that although mutation of His51 to alanine decreases the kinetics of fibril formation by increasing the lag-time, the resulting fibrils have a morphology that is similar to that of fibrils formed from WT $\beta_{2} \mathrm{~m}$ in vitro under the same solution conditions. The increase in the lag-time of fibril formation brought about by $\mathrm{H} 51 \mathrm{~A}$ is consistent with previous results on the involvement of this residue in amyloid fibril formation. ${ }^{33,42}$ Detailed ESI-IMS-MS analyses of the H51A oligomeric intermediates observed during the lag-time of fibril formation have revealed for the first time significant differences in the populations and subunit exchange dynamics of these oligomers compared with the corresponding oligomers arising from the WT $\beta_{2} \mathrm{~m}$ protein. Not only are higher order oligomers observed for $\mathrm{H} 51 \mathrm{~A}$, but all of the oligomers detected are significantly more populated and have increased stability compared with their WT counterparts.

One possible explanation for these differences is that the H51A oligomers observed here may be off-pathway species, thus slowing the rate of fibril formation by diverting H51A monomers to dead-end products. Alternatively the more stable, less dynamic H51A oligomers could be slower at converting to the amyloidogenic state compared with the oligomers formed from WT $\beta_{2}$ m (Fig. 6). Interestingly, although ESI-IMS-MS was required to separate, identify and estimate the populations of the individual oligomers from within heterogeneous mixtures, any differences in the conformational properties of the oligomers arising from the two different proteins were not evident from the ESI-IMS-MS

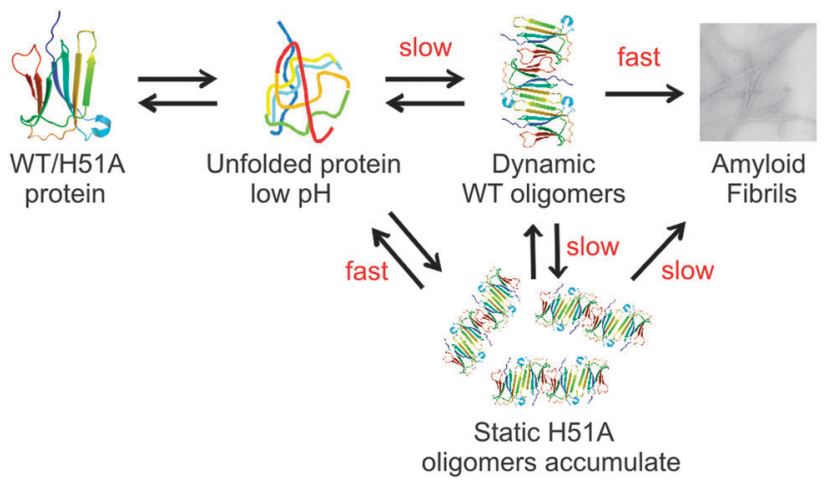

Fig. 6 Model of $\beta_{2}$ m amyloid fibril formation whereby WT $\beta_{2} m$ unfolds at low $\mathrm{pH}$ and forms dynamic oligomers that reach a critical nucleus and then convert rapidly into mature amyloid fibrils. In the case of H51A, the point mutation causes oligomers to form rapidly, although these more abundant, highly populated and kinetically stable oligomers are significantly more stable and less dynamic than the WT $\beta_{2}$ m oligomers and thus slower at converting into the critical nucleus that results in an increased lag-time of amyloid fibril formation.

data, with the $\beta_{2} \mathrm{~m}$ WT and H51A oligomeric species having similar CCS values indicative of shapes with similar overall dimensions.

Despite differences in the kinetics of amyloid fibril formation, the fibril yield of H51A and WT $\beta_{2} \mathrm{~m}$ remain comparable as analysed by SDS-PAGE analysis (Fig. 2E). This suggests that although more stable oligomers form extremely rapidly in the case of H51A compared with WT $\beta_{2} \mathrm{~m}$, at the end of the lag-time and exponential growth phase these oligomers are all converted to fibrils with the same morphology as WT $\beta_{2} \mathrm{~m}$ (Fig. 2B).

\section{Conclusions}

Numerous studies have investigated the effects of small molecule binding to amyloid-forming protein monomers, ${ }^{45-48}$ in addition to probing the effect of point mutations in the starting monomer sequence on amyloid fibril formation. ${ }^{9,49}$ However, to our knowledge, this is the first detailed study reporting on the correlation between the lag-time and the population and kinetic stability of oligomeric species. Thus, the H51A oligomers become kinetically trapped, increasing in population and converting slowly into amyloid fibrils. These results illustrate the importance of $\mathrm{H} 51$ in $\beta_{2} \mathrm{~m}$ fibril formation at low $\mathrm{pH}$. They also highlight the power of ESI-IMS-MS combined with subunit exchange dynamics in characterising the behaviour of individual oligomeric intermediates from a heterogeneous ensemble in real-time, revealing detailed insights into the nature and potential role of oligomeric intermediates in amyloid fibril formation.

\section{Acknowledgements}

ACL was funded by a BBSRC CASE PhD studentship in collaboration with Dr John Hoyes and Dr Mike Morris, Micromass UK Ltd/ Waters Corpn, Manchester, UK (BB/526502/1). CLP is funded by the Wellcome Trust (WT092896MA) and CAS by the BBSRC (BB/H024875/1). We acknowledge the BBSRC for funding the 
purchase of the Synapt HDMS mass spectrometer (BB/E012558/ 1). We also thank Dr Katy Routledge for the expression and purification of the ${ }^{14} \mathrm{~N}-\mathrm{H} 51 \mathrm{~A}$ protein used throughout these experiments and all members of the Ashcroft and Radford groups for useful discussions.

\section{References}

1 C. M. Dobson, Protein folding and misfolding, Nature, 2003, 426, 884-890.

2 F. U. Hartl, Molecular chaperones in cellular protein folding, Nature, 1996, 381, 571-580.

3 T. Eichner and S. E. Radford, A diversity of assembly mechanisms of a generic amyloid fold, Mol. Cell, 2011, 43, 8-18.

4 F. Chiti and C. M. Dobson, Protein misfolding, functional amyloid, and human disease, Annual Review of Biochemistry, Annual Reviews, Palo Alto, 2006, pp. 333-366.

5 F. Gejyo, T. Yamada, S. Odani, Y. Nakagawa, M. Arakawa, T. Kunitomo, H. Kataoka, M. Suzuki, Y. Hirasawa, T. Shirahama, A. S. Cohen and K. Schmid, A new form of amyloid protein associated with chronic-hemodialysis was identified as beta 2-microglobulin, Biochem. Biophys. Res. Commun., 1985, 129, 701-706.

6 T. Eichner and S. E. Radford, Understanding the complex mechanisms of beta 2-microglobulin amyloid assembly, FEBS J., 2011, 278, 3868-3883.

7 C. H. Trinh, D. P. Smith, A. P. Kalverda, S. E. V. Phillips and S. E. Radford, Crystal structure of monomeric human beta2-microglobulin reveals clues to its amyloidogenic properties, Proc. Natl. Acad. Sci. U. S. A., 2002, 99, 9771-9776.

8 T. Eichner and S. E. Radford, A generic mechanism of beta(2)-Microglobulin amyloid assembly at neutral $\mathrm{pH}$ involving a specific proline switch, J. Mol. Biol., 2009, 386, 1312-1326.

9 C. Santambrogio, S. Ricagno, M. Colombo, A. Barbiroli, F. Bonomi, V. Bellotti, M. Bolognesi and R. Grandori, DE-loop mutations affect beta 2-microglobulin stability, oligomerization, and the low-pH unfolded form, Protein Sci., 2010, 19, 1386-1394.

10 M. F. Calabrese and A. D. Miranker, Metal binding sheds light on mechanisms of amyloid assembly, Prion, 2009, 3, 1-4.

11 N. M. Kad, N. H. Thomson, D. P. Smith, D. A. Smith and S. E. Radford, Beta(2)-microglobulin and its deamidated variant, N17D form amyloid fibrils with a range of morphologies in vitro, J. Mol. Biol., 2001, 313, 559-571.

12 G. W. Platt, K. E. Routledge, S. W. Homans and S. E. Radford, Fibril growth kinetics reveal a region of beta(2)-microglobulin important for nucleation and elongation of aggregation, J. Mol. Biol., 2008, 378, 251-263.

13 W. S. Gosal, I. J. Morten, E. W. Hewitt, D. A. Smith, N. H. Thomson and S. E. Radford, Competing pathways determine fibril morphology in the self-assembly of beta(2)microglobulin into amyloid, J. Mol. Biol., 2005, 351, 850-864.
14 S. L. Myers, S. Jones, T. R. Jahn, I. J. Morten, G. A. Tennent, E. W. Hewitt and S. E. Radford, A systematic study of the effect of physiological factors on beta 2-microglobulin amyloid formation at neutral pH, Biochemistry, 2006, 45, 2311-2321.

15 D. P. Smith, S. Jones, L. C. Serpell, M. Sunde and S. E. Radford, A systematic investigation into the effect of protein destabilisation on beta 2-microglobulin amyloid formation, J. Mol. Biol., 2003, 330, 943-954.

16 C. L. Ladner, M. Chen, D. P. Smith, G. W. Platt, S. E. Radford and R. Langen, Stacked sets of parallel, in-register betastrands of beta(2)-microglobulin in amyloid fibrils revealed by site-directed spin labeling and chemical labeling, J. Biol. Chem., 2010, 285, 17137-17147.

17 G. T. Debelouchina, G. W. Platt, M. J. Bayro, S. E. Radford and R. G. Griffin, Intermolecular alignment in beta(2)microglobulin amyloid fibrils, J. Am. Chem. Soc., 2010, 132, 17077-17079.

18 H. E. White, J. L. Hodgkinson, T. R. Jahn, S. Cohen-Krausz, W. S. Gosal, S. Muller, E. V. Orlova, S. E. Radford and H. R. Saibil, Globular tetramers of beta(2)-microglobulin assemble into elaborate amyloid fibrils, J. Mol. Biol., 2009, 389, 48-57.

19 A. E. Ashcroft, Mass spectrometry and the amyloid problemhow far can we go in the gas phase?, J. Am. Soc. Mass Spectrom., 2010, 21, 1087-1096.

20 D. M. Williams and T. L. Pukala, Novel insights into protein misfolding diseases revealed by ion mobility-mass spectrometry, Mass Spectrom. Rev., 2013, 32, 169-187.

21 L. F. Lue, Y. M. Kuo, A. E. Roher, L. Brachova, Y. Shen, L. Sue, T. Beach, J. H. Kurth, R. E. Rydel and J. Rogers, Soluble amyloid beta peptide concentration as a predictor of synaptic change in Alzheimer's disease, Am. J. Pathol., 1999, 155, 853-862.

22 J. Wang, D. W. Dickson, J. Q. Trojanowski and V. M. Y. Lee, The levels of soluble versus insoluble brain A-beta distinguish Alzheimer's disease from normal and pathologic aging, Exp. Neurol., 1999, 158, 328-337.

23 J. L. Tomic, A. Pensalfini, E. Head and C. G. Glabe, Soluble fibrillar oligomer levels are elevated in Alzheimer's disease brain and correlate with cognitive dysfunction, Neurobiol. Dis., 2009, 35, 352-358.

24 B. Winner, R. Jappelli, S. K. Maji, P. A. Desplats, L. Boyer, S. Aigner, C. Hetzer, T. Loher, M. Vilar, S. Campionic, C. Tzitzilonis, A. Soragni, S. Jessberger, H. Mira, A. Consiglio, E. Pham, E. Masliah, F. G. Gage and R. Riek, In vivo demonstration that alpha-synuclein oligomers are toxic, Proc. Natl. Acad. Sci. U. S. A., 2011, 108, 4194-4199.

25 N. Reixach, S. Deechongkit, X. Jiang, J. W. Kelly and J. N. Buxbaum, Tissue damage in the amyloidoses: Transthyretin monomers and non-native oligomers are the major cytotoxic species in tissue culture, Proc. Natl. Acad. Sci. U. S. A., 2004, 101, 2817-2822.

26 M. Bucciantini, E. Giannoni, F. Chiti, F. Baroni, L. Formigli, J. S. Zurdo, N. Taddei, G. Ramponi, C. M. Dobson and M. Stefani, Inherent toxicity of aggregates implies a 
common mechanism for protein misfolding diseases, Nature, 2002, 416, 507-511.

27 D. P. Smith, S. E. Radford and A. E. Ashcroft, Elongated oligomers in beta(2)-microglobulin amyloid assembly revealed by ion mobility spectrometry-mass spectrometry, Proc. Natl. Acad. Sci. U. S. A., 2010, 107, 6794-6798.

28 D. P. Smith, L. A. Woods, S. E. Radford and A. E. Ashcroft, Structure and dynamics of oligomeric intermediates in beta(2)microglobulin self-assembly, Biophys. J., 2011, 101, 1238-1247.

29 G. Esposito, S. Ricagno, A. Corazza, E. Rennella, D. Gumral, M. C. Mimmi, E. Betto, C. E. M. Pucillo, F. Fogolari, P. Viglino, S. Raimondi, S. Giorgetti, B. Bolognesi, G. Merlini, M. Stoppini, M. Bolognesi and V. Bellotti, Aggregation properties the controlling roles of Trp60 and Trp95 in beta(2)-microglobulin function, folding and amyloid aggregation properties, J. Mol. Biol., 2008, 378, 887-897.

30 J. P. Hodkinson, T. R. Jahn, S. E. Radford and A. E. Ashcroft, HDX-ESI-MS reveals enhanced conformational dynamics of the amyloidogenic protein beta(2)-microglobulin upon release from the MHC-1, J. Am. Soc. Mass Spectrom., 2009, 20, 278-286.

31 C. Liu, M. Zhao, L. Jiang, P. Cheng, J. Park, M. R. Sawaya, A. Pensalfinic, D. Goud, A. J. Berk, C. G. Glabe, J. Nowick and D. Eisenberg, Out-of-register $\beta$-sheets suggest a pathway to toxic amyloid aggregates, Proc. Natl. Acad. Sci. U. S. A., 2012, 109, 20913-20918.

32 S. Ricagno, M. Colombo, M. de Rosa, E. Sangiovanni, S. Giorgetti, S. Raimondi, V. Bellotti and M. Bolognesi, DE loop mutations affect beta 2-microglobulin stability and amyloid aggregation, Biochem. Biophys. Res. Commun., 2008, 377, 146-150.

33 K. E. Routledge, G. G. Tartaglia, G. W. Platt, M. Vendrusco and S. E. Radford, Competition between intramolecular and intermolecular interactions in an amyloid-forming protein, J. Mol. Biol., 2009, 389, 776-786.

34 P. Hortschansky, V. Schroeckh, T. Christopeit, G. Zandomeneghi and M. Fandrich, The aggregation kinetics of Alzheimer's betaamyloid peptide is controlled by stochastic nucleation, Protein Sci., 2005, 14, 1753-1759.

35 M. J. Shields, N. Assefi, W. Hodgson, E. J. Kim and R. K. Ribaudo, Characterization of the interactions between MHC class I subunits: A systematic approach for the engineering of higher affinity variants of beta(2)-microglobulin, J. Immunol., 1998, 160, 2297-2307.

36 S. Azinas, M. Colombo, A. Barbiroli, C. Santambrogio, S. Giorgetti, S. Raimondi, F. Bonomi, R. Grandori, V. Bellotti, S. Ricagno and M. Bolognesi, D-strand perturbation and amyloid propensity in beta-2 microglobulin, FEBS J., 2011, 278, 2349-2358.

37 M. Okon, P. Bray and D. Vucelic, H-1-NMR assignments and secondary structure of human beta-2-microglobulin in solution, Biochemistry, 1992, 31, 8906-8915.
38 G. Verdone, A. Corazza, P. Viglino, F. Pettirossi, S. Giorgetti, P. Mangione, A. Andreola, M. Stoppini, V. Bellotti and G. Esposito, The solution structure of human beta 2-microglobulin reveals the prodromes of its amyloid transition, Protein Sci., 2002, 11, 487-499.

39 S. Park and J. G. Saven, Simulation of pH-dependent edge strand rearrangement in human beta 2-microglobulin, Protein Sci., 2006, 15, 200-207.

40 V. L. Mendoza, K. Antwi, M. A. Baron-Rodriguez, C. Blanco and R. W. Vachet, Structure of the pre-amyloid dimer of beta-2-microglobulin from covalent labeling and mass spectrometry, Biochemistry, 2010, 49, 1522-1532.

41 V. L. Mendoza, M. A. Baron-Rodriguez, C. Blanco and R. W. Vachet, Structural insights into the pre-amyloid tetramer of beta-2-microglobulin from covalent labeling and mass spectrometry, Biochemistry, 2011, 50, 6711-6722.

42 T. Chiba, Y. Hagihara, T. Higurashi, K. Hasegawa, H. Naiki and Y. Goto, Amyloid fibril formation in the context of fulllength protein - effects of proline mutations on the amyloid fibril formation of beta(2)-microglobulin, J. Biol. Chem., 2003, 278, 47016-47024.

43 P. Schuck, Size-distribution analysis of macromolecules by sedimentation velocity ultracentrifugation and Lamm equation modelling, Biophys. J., 2000, 78, 1606-1619.

44 A. M. Smith, T. R. Jahn, A. E. Ashcroft and S. E. Radford, Direct observation of oligomeric species formed in the early stages of amyloid fibril formation using electrospray ionisation-mass spectrometry, J. Mol. Biol., 2006, 364, 9-19.

45 M. Colombo, M. de Rosa, V. Bellotti, S. Ricagno and M. Bolognesi, A recurrent D-strand association interface is observed in beta 2-microglobulin oligomers, FEBS J., 2012, 279, 1131-1143.

46 L. A. Woods, G. W. Platt, A. L. Hellewell, E. W. Hewitt, S. W. Homans, A. E. Ashcroft and S. E. Radford, Ligand binding to distinct states diverts aggregation of an amyloidforming protein, Nat. Chem. Biol., 2011, 7, 730-739.

47 D. E. Ehrnhoefer, J. Bieschke, A. Boeddrich, M. Herbst, L. Masino, R. Lurz, S. Engemann, A. Pastore and E. E. Wanker, EGCG redirects amyloidogenic polypeptides into unstructured, off-pathway oligomers, Nat. Struct. Mol. Biol., 2008, 15, 558-566.

48 S. J. Hyung, A. S. DeToma, J. R. Brender, S. Lee, S. Vivekanandan, A. Kochi, J. S. Choi, A. Ramamoorthy, B. T. Ruotolo and M. H. Lim, Insights into antiamyloidogenic properties of the green tea extract (-)-epigallocatechin-3-gallate toward metal-associated amyloid-beta species, Proc. Natl. Acad. Sci. U. S. A., 2013, 110, 3743-3748.

49 M. M. Gessel, S. Bernstein, M. Kemper, D. B. Teplow and M. T. Bowers, Familial Alzheimer's disease mutations differentially alter amyloid beta-protein oligomerization, ACS Chem. Neurosci., 2012, 3, 909-918. 